\title{
卧龙自然保护区典型生态系统服务时空变化研究
}

\author{
曹梦琪, 蔡英楠, 张 丽, 徐建英* \\ 首都师范大学资源环境与旅游学院,三维信息获取与应用教育部重点实验室, 北京 100048
}

\begin{abstract}
摘要: 自然保护区作为生态系统服务的产生区和生物多样性保护的重点区,评估其关键生态系统服务,对提高保护区管理水平 和生态保护与建设效率有重要意义。利用 CASA 模型、RUSLE 模型、InVEST 模型及水量平衡原理等方法分别定量评估了卧龙 自然保护区 2000 年和 2015 年碳固定 (NPP) 、土壤保持、生境质量和水源涵养 4 种生态系统服务并分析了其时空分布及其变化 特征, 揭示了不同地形位梯度和土地利用类型上生态系统服务的差异, 识别了生态系统服务的热点区域。研究结果揭示了 2000-2015 年 4 种生态系统服务及其变化的时空异质性: 1) 研究期间保护区 4 种生态系统服务供给量均有所增加, 且增益面 积大于减损面积;2) 空间上,NPP、土壤保持和生境质量 3 种服务表现为东南高、西北低,水源涵养空间分布无明显规律,4 种服 务的空间分布特征均变化不大且保持相对稳定;3)4 种生态系统服务空间分布及变化与地形位和土地利用类型有关。4 种服务 的高值和增益的优势分布区均位于较低地形位指数梯度上, 以保护区东南部最为突出; 林地和草地是对保护区生态系统服务贡 献较大的土地利用类型, 尤以林地突出; 4 ) 热点分析表明保护区东南部是主要的生态系统服务供给热点区, 研究期间 IV 类热点 区面积显著增加。结合研究区域生态系统特征和生态恢复与管理政策,探讨分析了目标生态系统服务时空变化的自然生态和 社会经济驱动力,为本区域生态系统恢复和生物多样性保护提供依据和建议。
\end{abstract}

关键词: 卧龙自然保护区; 生态系统服务; 时空变化;地形位指数;土地利用类型;热点分析

\section{Temporal and spatial variation of typical ecosystem services in Wolong Nature Reserve}

CAO Mengqi, CAI Yingnan, ZHANG Li, XU Jianying*

College of Resource, Environmental and Tourism, Capital Normal University, Key Laboratory of 3-Dimensional Information Acquisition and Application, Ministry of Education, Beijing 100048, China

\begin{abstract}
Nature reserves are the cornerstones to conserve biodiversity and the effective way to sustain ecosystem integrity. It is significant to evaluate key ecosystem services in nature reserve and integrate them into the reserve management to improve the efficiency of ecological conservation and rehabilitation. Based on the CASA model, RUSLE model, InVEST model and the principle of water balance, this research evaluated the spatial and temporal distribution of four key ecosystem services in the Wolong Nature Reserve, including carbon storage ( Net Primary Productivity), soil conservation, habitat quality and water conservation, covering period from 2000 to 2015. What's more, the variability of the four key ecosystem services at different terrain niche gradients and land use types were also analyzed and the hotspots of the four key ecosystem services were identified. Research results indicated that significant spatio-temporal heterogeneity existed for both four key ecosystem services provision and their changes during research period. Some conclusions could be derived as following: i) the average provision of four key ecosystem services increased during research period, and more areas with increase of key ecosystem services were found than those areas with decrease of key ecosystem services; ii) Distinct characteristic of spatial
\end{abstract}

基金项目:国家自然科学基金项目 (41271552)

收稿日期: 2020-01-12; 网络出版日期:2021-07-24

*通讯作者 Corresponding author.E-mail: xu-jianying@163.com 
distribution heterogeneity were found. Areas with higher provision of the NPP ( Net Primary Productivity), soil conservation and habitat quality were distributed in the southeast, while areas with lower provision of them were distributed in the northwest. The characteristic of spatial distribution did not change much and sustained relatively stable during research period; iii) Spatial distribution and changes of four key ecosystem services were related to terrain niche gradient and land use types. The areas with high provision and increase of the four key ecosystem services were dominantly located in lower terrain niche gradient, especially in the southeast area. With respect to the land use types, forestland and grassland had the outstanding contributions to the four key ecosystem services provision, and the most contribution came from forestland; iv) Hotspot analysis indicated that the hotspots of the four key ecosystem services were mainly distributed in the southeast of the study area, and the area of the hotspot of class IV, where four key ecosystem services provision were all higher than the average provision of whole study area, had increased significantly during the study period. According to the transfer matrix of hotspots, the variation characteristics of the hotspots showed a tendency towards ecological improvement. Finally, underlying driving forces were discussed, the spatio-temporal distribution and changes of four key ecosystem services could be closely related to local physical and socio-economic context. We hope the research results could be integrated into local ecological management policy and is helpful to improve local ecosystem restoration and biodiversity conservation.

Key Words: Wolong Nature Reserve; ecosystem services; spatio-temporal change; terrain niche; land use type; hotspot analysis

生态系统服务 (Ecosystem Services, ESs) 是指生态系统形成和提供给人们生存发展的直接产品或间接惠 益。根据联合国千年生态系统评估,生态系统服务分为供应、调节、文化和支持服务 4 种类型 ${ }^{[1]}$ 。一定时间和 空间尺度上的生物与非生物特征及其生态过程构成了生态系统结构与功能的差异,成为了生态系统服务产生 的基础 ${ }^{[2]}$ 。不同区域的地形地貌特征、土地利用变化、气候变化以及人类活动等因素会改变生态系统的结构 与空间特征,进而影响生态系统服务的时空分布差异和变化 ${ }^{[3-9]}$ 。全面了解特定时空下生态系统服务的时空 差异, 可为生态系统服务保护、管理和优化提供依据, 促进自然资源的管理保护以及针对性的生态恢复 ${ }^{[10-14]}$ 。

生态系统服务的时空变化是当前的研究热点 ${ }^{[15-17]}$, 国内外学者已进行了大量的研究, 业已形成相对成熟 便捷的数量评估模型, 如 CASA、RUSLE 和 InVEST 等, 研究主题包括生态系统服务时空分布和变化趋

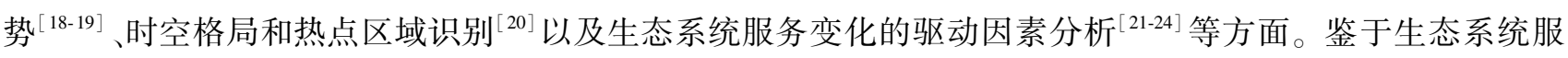
务时空变化分析对于生态和社会经济系统的显著意义,这些研究往往关注生态环境比较脆弱的区域或人类干 扰比较显著的区域,如王晓峰等研究了新疆地区 3 种生态系统服务的分区差异 ${ }^{[18]}$;潘竟虎等以干旱内陆河流 域典型地区嘉峪关-酒泉地区为例, 定量分析了 2000 和 2010 年 4 种生态系统服务的时空变化 ${ }^{[19]}$; 许丁雪等研 究了张家口-承德地区土地利用变化对生态系统服务的驱动作用 ${ }^{[21]}$, 上述研究揭示我国生态环境脆弱区生态 系统服务的时空变化并为区域生态恢复和建设提供了借鉴。而再凤维 ${ }^{[20]}$ 等、María Anaya-Romero ${ }^{[22]}$ 等、苏常 红 ${ }^{[23]}$ 等、潘梅 ${ }^{[24]}$ 等学者分别研究了人口集中、人类干扰比较显著的鄱阳湖地区、地中海地区、汾河流域和京 津冀地区, 强调了人类活动对于生态系统服务变化的影响, 分析了生态系统服务变化的驱动力。自然保护区 是生态系统保护的关键地区和生态系统服务供给的重点区域, 目前的相关研究主要集中于对各种保护项目和 措施的成效分析 ${ }^{[25-26]}$, 少有针对保护区典型生态系统服务的定量研究 ${ }^{[27]}$ 。同其他区域相比,保护区提供生态 系统服务的能力尤为显著 ${ }^{[28]}$, 是我国生态文明建设的重点, 也是我国诸多生态保护/建设项目实施的重点区 域。因此,对自然保护区生态系统服务进行定量研究,结合区域生态系统特征和生态保护/建设项目探讨分析 其时空变化特征以及自然和人为驱动因素, 可以为自然保护区生态系统保护、恢复和管理提供决策依据和 建议。

本研究拟以卧龙自然保护区为例进行研究。卧龙自然保护区位于四川省汶川县, 主要保护西南高山林区 自然生态系统及大熊猫等珍稀动物, 因大熊猫的保护在国内外著称, 隶属我国主要的固碳贡献区一一西南林 
地 ${ }^{[29]}$ 。此外,保护区位于岷江上游, 是岷江流域重要的水源涵养地, 其水源涵养和土壤保持功能对维持区域 生态安全有重要作用。因此, 针对卧龙自然保护区保护对象及其承担的生态功能, 本研究选择碳固定 (NPP) 、土壤保持、水源涵养和生境质量 4 种典型生态系统服务进行定量评估, 分析主要生态建设工程实施以 来保护区典型生态系统服务的时空分布和变化特征,确定生态系统服务供给的热点区域,以为生态保护/建设 政策的实施和保护区的生态系统管理提供建议。

\section{1 研究方法与数据来源}

\section{1 研究区概况}

卧龙自然保护区 $\left(\right.$ 东经 $102^{\circ} 52^{\prime}-103^{\circ} 25^{\prime}$, 北纬 $30^{\circ}$ $\left.45^{\prime}-31^{\circ} 25^{\prime}\right)$ 位于四川省阿坝藏族芫族自治州汶川县 境内, 四川盆地的西缘, 岷江的上游, 是青藏高原向成都 平原的过渡地带, 地势西北高、东南低, 南北长约 62 $\mathrm{km}$, 东西宽约 $52 \mathrm{~km}$, 总面积约为 $2000 \mathrm{~km}^{2}$ (图 1)。保 护区属典型的亚热内陆山地气候, 年温差小, 干湿季节 分明,植被和土壤随海拔变化的垂直分布规律明显。区 内动植物资源丰富, 拥有近 4000 种植物以及大熊猫、金 丝猴等多种珍稀濒危动物。水能资源丰富,生态系统类 型复杂多样,是生态系统服务研究的典型区域。

\section{2 数据来源及预处理}

本文使用的基础数据包括:土壤数据、植被数据、气

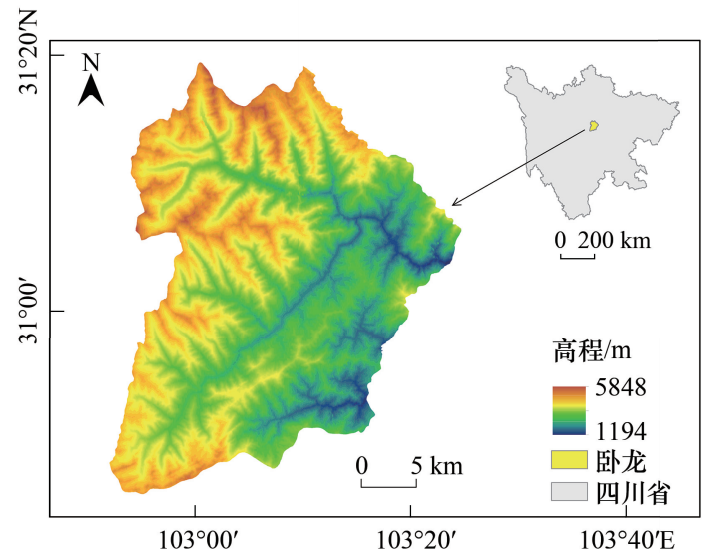

图 1 研究区位置及地形示意图

Fig.1 Location and elevation of the study area 象数据、高程数据和土地利用类型数据(表 1 )。研究时 间为 2000 年和 2015 年两个年份的 5-10 月,该时段降水丰沛, 雨热同期,是植被生长的最佳季节。

\section{表 1 数据来源及预处理}

Table 1 Data sources and pretreatment

\begin{tabular}{|c|c|}
\hline 数据类型 Data & 数据来源及预处理方法 Data sources and pretreatment \\
\hline 土壤数据 & 黑河计划数据管理中心、寒区旱区科学数据中心 (http://wes tdc.westgis.ac.cn), 空间分辨率 $1 \mathrm{~km}$, 重采样 \\
\hline Soil data & 后得到分辨率 $30 \mathrm{~m}$ 的土壤数据, 将结果与原数据进行对比,未发现较大差异,可用于本研究 \\
\hline $\begin{array}{l}\text { 植被数据 } \\
\text { Vegetation data }\end{array}$ & 地理国情监测云平台 (http://www.dsac.cn) 提供的的归一化植被指数 (NDVI) 产品数据, 空间分辨率 $30 \mathrm{~m}$ \\
\hline & 国家气象信息中心 (http://data.cma.cn), 选取四川省气象台站逐月气象资料,包括降雨量、气温和太阳辐 \\
\hline 气象数据 & 射等, 通过 ArcGIS 普通克里金法对气象数据进行空间插值并裁剪得到研究区气象空间数据, 空间分辨率 \\
\hline Meteorological data & $\begin{array}{l}30 \mathrm{~m} \text { 。蒸发量 (ET) 源自美国地质勘察局 (USGS) (ftp://ladsweb.nascom. nasa.gov/allData/) 提供的 MODIS } \\
\text { 影像 MOD16A3 产品,空间分辨率 } 500 \mathrm{~m} \text {,重采样后得到分辨率 } 30 \mathrm{~m} \text { 数据 }\end{array}$ \\
\hline $\begin{array}{l}\text { 高程数据 } \\
\text { DEM data }\end{array}$ & $\begin{array}{l}\text { 地理空间数据云平台 (http://www.gscloud.cn) (ASTER GDEM 数据产品), 空间分辨率 } 30 \mathrm{~m} \text {, 根据 DEM 数 } \\
\text { 据提取研究区海拔、坡度、河水流向等要素 }\end{array}$ \\
\hline 土地利用数据 & 中国科学院资源环境科学数据中心 (http://www.resdc.cn) 提供的土地利用遥感监测数据, 空间分辨率 30 \\
\hline
\end{tabular}

NDVI: 归一化植被指数 Normalized Difference Vegetation Index;ET:蒸发量 Evaporation;DEM:数字高程模型 Digital Elevation Model

\section{3 研究方法}

\subsection{1 碳固定 (NPP)}

本研究碳固定服务用植被净初级生产力 ( Net Primary Productivity, NPP) 予以指代。采用朱文泉 ${ }^{[30]}$ 改进 的 CASA ( Carnegie-Ames-Stanford Approach) 模型估算研究区 2000 年和 2015 年的 NPP,其计算公式如下:

$$
\mathrm{NPP}=\mathrm{APAR} \times \varepsilon
$$

$\mathrm{APAR}=\mathrm{SOL} \times \mathrm{FPAR} \times 0.5$ 


$$
\varepsilon=T_{\varepsilon 1} \times T_{\varepsilon 2} \times W_{\varepsilon} \times \varepsilon_{\text {max }}
$$

式中, APAR 表示植被吸收光合有效辐射 $\left(\mathrm{MJ} / \mathrm{m}^{2}\right) ; \varepsilon$ 表示实际光能利用率 $(\mathrm{gC} / \mathrm{MJ}) ; \mathrm{SOL}$ 表示太阳总辐射量 $\left(\mathrm{MJ} / \mathrm{m}^{2}\right), \mathrm{FPAR}$ 表示植被层对人射的光合有效辐射 (PAR) 的吸收率, 可通过归一化植被指数 (NDVI) 对其进 行估算; 常数 0.5 表示植被所利用的太阳有效辐射占太阳总辐射的比例; $T_{\varepsilon 1}$ 和 $T_{\varepsilon 2}$ 表示温度对光能利用率的 影响; $W_{\varepsilon}$ 表示水分条件对光能利用率的影响; $\varepsilon_{\text {max }}$ 表示在理想状态下植被的最大光能利用率 (参考朱文泉等的 研究成果)。

\subsection{2 土壤保持}

修正通用土壤流失方程 (Revised Universal Soil Loss Equation, RUSLE) 经众多学者采用来评估土壤保持 量, 均取得较好效果 ${ }^{[31-33]}$, 计算公式如下:

$$
\begin{aligned}
& A_{m}=R \times K \times L S \times C \times P \\
& A_{p}=R \times K \times L S \\
& A_{c}=A_{p}-A_{m}
\end{aligned}
$$

式中, $A_{m}$ 为实际土壤侵蚀量 $\left(\mathrm{t} \mathrm{hm} \mathrm{hm}^{-2} \mathrm{a}^{-1}\right)$, 指当前地表覆盖和水土保持措施下的土壤侵蚀量; $A_{p}$ 为潜在土壤侵

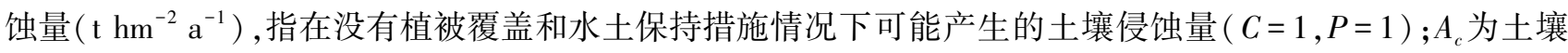

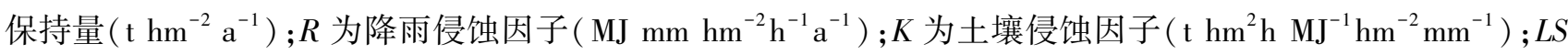
为坡长坡度因子 $; C$ 为植被覆盖因子; $P$ 为水土保持措施因子。

(1) 降雨侵蚀因子 $R$ 采用 Wischmeier 等提出的基于月尺度降雨量数据的经验计算公式 ${ }^{[34-35]}$ :

$$
R=\sum_{i}^{n} 1.735 \times 10^{1.5 \times \log 10 \frac{p_{i}^{2}}{p}-0.08188}
$$

式中, $p_{i}$ 为第 $i$ 个月的降水量 $(\mathrm{mm}), p$ 为年降水量 $(\mathrm{mm})$ 。

(2) 土壤侵蚀因子 $K$ 采用 EPIC 模型进行估算, 计算公式如下 ${ }^{[36]}$ :

$$
\begin{aligned}
& K_{\mathrm{EPIC}}=\left(0.2+0.3 \times e^{-0.0256 \times m_{s} \times\left(1-\frac{m_{\text {silt }}}{100}\right)}\right) \times\left(\frac{m_{\text {silt }}}{m_{c}+m_{\text {silt }}}\right)^{0.3} \times\left(1-\frac{0.25 \times \text { orgC }}{\text { orgC }+e^{3.72-2,95 \times \text { org }}}\right) \times \\
&\left(\begin{array}{c}
0.7 \times\left(1-\frac{m_{s}}{100}\right) \\
\left(1-\frac{m_{s}}{100}\right)+e^{-5.51+22.9\left(1-\frac{m_{s}}{100}\right)}
\end{array}\right) \\
& K=\left(-0.01383+0.51575 \times K_{\text {EPIC }}\right) \times 0.1317
\end{aligned}
$$

式中, $m_{s}$ 为砂粒含量; $m_{\text {silt }}$ 为粉粒含量 $; m_{c}$ 为粘粒含量 $;$ orgC 为有机质含量。

(3) 坡长坡度因子 $L S$ 的计算公式如下 ${ }^{[32]}$ :

$$
\begin{aligned}
L & =(\lambda / 22.1)^{m} \\
m & = \begin{cases}0.2 & \theta<1^{\circ} \\
0.3 & 1^{\circ} \leqslant \theta<3^{\circ} \\
0.4 & 3^{\circ} \leqslant \theta \leqslant 5^{\circ} \\
0.5 & 5^{\circ}<\theta\end{cases} \\
S & = \begin{cases}10.8 \sin \theta+0.03 & \theta<5^{\circ} \\
16.8 \sin \theta-0.50 & 5^{\circ} \leqslant \theta<10^{\circ} \\
21.9 \sin \theta-0.96 & 10^{\circ} \leqslant \theta\end{cases}
\end{aligned}
$$

式中, $\lambda$ 为坡长 $(\mathrm{m}) ; m$ 为坡长效应指数; $\theta$ 为坡度 $\left({ }^{\circ}\right)$ 。

(4) 植被覆盖因子 $C$ 的计算公式如下 ${ }^{[37]}$ : 


$$
\begin{aligned}
& C=\left\{\begin{array}{lc}
1 & f<0.1 \\
0.6508-0.3436 \ln f & 0.1 \leqslant f \leqslant 0.783 \\
0 & 0.783<f
\end{array}\right. \\
& f=\frac{\mathrm{NDVI}-\mathrm{NDVI}_{\text {soil }}}{\mathrm{NDVI}_{\text {veg }}-\mathrm{NDVI}_{\text {soil }}}
\end{aligned}
$$

式中, $f$ 为植被覆盖度; NDVI 为植被归一化指数, $N D V I_{\text {soil }}$ 和NDVI ${ }_{\text {veg }}$ 分别为土壤和植被的 NDVI。

(5) 水土保持措施因子 $P$ 指在采取保持措施情况下与顺坡耕作时土壤流失量的比值。 $P=0$ 表示不发生 侵蚀, $P=1$ 表示未采取任何水土保持措施。由于缺乏相关数据, 本研究不考虑 $P$ 因子影响, $P$ 值定义为 1 。

\subsection{3 生境质量}

生境质量指生态系统为物种生存繁衍提供的条件或潜力 ${ }^{[38]}$ 。本文中特指保护区生态系统可为大熊猫生 存繁衍所利用的环境条件状况。InVEST 模型生境质量模块以土地覆被为基础,利用外界威胁强度(影响的距 离和权重)、生境适宜性、生境类型对威胁的敏感性进行生境质量评估。参照以往研究成果 ${ }^{[39-41]}$ 和保护区实 际情况,本研究选取耕地、主要道路、乡村小路和城镇居民用地作为威胁源 (表 2) 并对各土地利用类型的生境 适宜性进行打分以及对威胁源敏感性赋值 (表 3 )。生境适宜性得分为 $0-1$, 其中 1 表示该生境具有最高适宜 性,而非生境取值为 0 。计算公式如下:

$$
\begin{aligned}
Q_{x j} & =H_{j}\left(1-\left(\frac{D_{x j}^{Z}}{D_{x j}^{Z}-k^{Z}}\right)\right) \\
D_{x j} & =\sum_{r=1}^{R} \sum_{y=1}^{Y_{r}}\left(\frac{W_{r}}{\sum_{r=1}^{R} W_{r}}\right) r_{y} i_{r x y} \beta_{x} S_{j r}
\end{aligned}
$$

式中, $Q_{x j}$ 是土地利用类型 $j$ 中栅格 $x$ 的生境质量; $D_{x j}$ 是土地利用类型 $j$ 中栅格 $x$ 的生境胁迫水平; $k$ 为计算的 半饱和参数; $H_{j}$ 为土地利用类型 $j$ 的生境适宜性; $R$ 为胁迫因子; $Y_{r}$ 为胁迫因子 $r$ 所占的栅格数; $W_{r}$ 为胁迫因子 权重, 值为 $0-1 ; r_{y}$ 为栅格 $y$ 的胁迫因子值; $i_{r x y}$ 为 $r_{y}$ 对栅格 $x$ 的胁迫水平; $\beta_{x}$ 为栅格 $x$ 的可达性水平; $S_{j r}$ 为土地

\begin{tabular}{|c|c|c|c|c|c|}
\hline $\begin{array}{l}\text { 威胁源 } \\
\text { Threat }\end{array}$ & $\begin{array}{c}\text { 最大影响距离 } \\
\text { Maximum impact distance/km }\end{array}$ & $\begin{array}{l}\text { 权重 } \\
\text { Weight }\end{array}$ & $\begin{array}{l}\text { 威胁源 } \\
\text { Threat }\end{array}$ & $\begin{array}{c}\text { 最大影响距离 } \\
\text { Maximum impact distance/km }\end{array}$ & $\begin{array}{c}\text { 权重 } \\
\text { Weight }\end{array}$ \\
\hline 耕地 Cropland & 0.75 & 0.70 & 乡村小路 Path & 0.03 & 0.50 \\
\hline 主要道路 Road & 0.72 & 0.70 & 城镇居民用地 Urban area & 1.92 & 1.00 \\
\hline
\end{tabular}
利用类型 $j$ 对胁迫因子 $r$ 的敏感性。

表 2 威胁源的最大影响距离及权重

Table 2 Maximum impact distance and weight of threat

表 3 土地利用类型对威胁源的敏感性参数

Table 3 Land use type sensitivity parameter to threat

\begin{tabular}{lccccc}
\hline $\begin{array}{l}\text { 土地利用类型 } \\
\text { Land use types }\end{array}$ & $\begin{array}{c}\text { 生境适宜性得分 } \\
\text { Habitat score }\end{array}$ & $\begin{array}{c}\text { 耕地 } \\
\text { Cropland }\end{array}$ & $\begin{array}{c}\text { 主要道路 } \\
\text { Road }\end{array}$ & $\begin{array}{c}\text { 乡村小路 } \\
\text { Path }\end{array}$ & $\begin{array}{c}\text { 城镇居民用地 } \\
\text { Urban area }\end{array}$ \\
\hline 耕地 Cropland & 0 & 0 & 0 & 0 & 0 \\
有林地 Forestland & 1 & 0.5 & 0.5 & 0.3 & 0.8 \\
灌木林地 Shrubland & 0.6 & 0.6 & 0.6 & 0.55 & 0.8 \\
其他林地 Sparse woodland & 0.3 & 0.65 & 0.4 & 0 & 0.75 \\
草地 Grassland & 0 & 0 & 0 & 0 & 0 \\
农村居民点 Residential area & 0 & 0 & 0 & 0 & 0 \\
裸地 Barren land & 0 & 0 & 0 & 0 \\
\hline
\end{tabular}

基于以上模型计算结果, 根据欧阳志云 ${ }^{[39]}$ 等提出的大熊猫生境自然环境因素评价准则中的适宜海拔和 坡度对结果进行进一步修正, 将研究区海拔和坡度分为适宜和不适宜两部分, 与模型结果进行叠加。 


\subsection{4 水源涵养}

计算水源涵养, 首先通过水量平衡原理得到保护区产水量, 再根据土壤深度、土壤饱和导水率、地形指数 和流速系数等对产水量进行修正得到水源涵养量,计算公式如下 ${ }^{[42-43]}$ :

$$
\begin{gathered}
Y=P-E T \\
W R=\min (1,249 / V) \times \min (1,0.9 \times D / 3) \times \min \left(1, K_{\text {soil }} / 300\right) \times Y \\
D=\log \left(\frac{\mathrm{Wpc}}{s d \times p s}\right)
\end{gathered}
$$

式中, $Y$ 为产水量 $(\mathrm{mm}) ; P$ 为降水量 $(\mathrm{mm}) ; E T$ 为蒸发量 $(\mathrm{mm}) ; W R$ 为多年平均水源涵养量 $(\mathrm{mm}) ; V$ 为流速 系数 (采用模型参数表数据 $\left.{ }^{[44]}\right) ; D$ 为地形指数, 无量纲 $; K_{\text {soil }}$ 为土壤饱和导水率 $(\mathrm{cm} / \mathrm{d}) ; \mathrm{Wpc}($ Watershed pixel count) 为集水区栅格数, 无量纲; $S d$ (Soil depth) 为土壤深度 $(\mathrm{mm}) ; P s$ (Percent slope) 为百分比坡度。由于缺乏 2000 年 $E T$ 数据, 本研究使用 2001 年数据代替。

\subsection{5 地形位指数}

地形位指数是复合分析海拔和坡度属性信息的指标,能够综合反映空间内某点的地形条件。其计算公式 如下 ${ }^{[45]}$ :

$$
T=\ln \left[\left(\frac{E}{E_{0}}+1\right) \times\left(\frac{S}{S_{0}}+1\right)\right]
$$

式中, $T$ 为地形位指数, $E$ 及 $E_{0}$ 分别为空间内任一栅格的高程 $(\mathrm{m})$ 和平均高程 $(\mathrm{m}), S$ 和 $S_{0}$ 分别为空间内任一 栅格的坡度值 $\left(^{\circ}\right)$ 和平均坡度值 $\left({ }^{\circ}\right)$ 。一般地, 海拔低、坡度小的栅格地形位指数小, 反之越大; 海拔低坡度大 或海拔高坡度小的栅格,其地形位指数居中。本研究根据计算结果采用自然断点法将研究区地形位指数划分 为 10 个梯度 $($ 表 4$)$ 。

表 4 地形位指数分级标准

Table 4 Classification of terrain niche

\begin{tabular}{cccccc}
\hline $\begin{array}{c}\text { 梯度分级 } \\
\text { Classification }\end{array}$ & $\begin{array}{c}\text { 地形位指数 } \\
\text { Terrain niche }\end{array}$ & $\begin{array}{c}\text { 面积比例 } \\
\text { Area proportion/\% }\end{array}$ & $\begin{array}{c}\text { 梯度分级 } \\
\text { Classification }\end{array}$ & $\begin{array}{c}\text { 地形位指数 } \\
\text { Terrain niche }\end{array}$ & $\begin{array}{c}\text { 面积比例 } \\
\text { Area proportion/\% }\end{array}$ \\
\hline 1 & $0.32-0.78$ & 1.14 & 6 & $1.29-1.39$ & 17.02 \\
2 & $0.78-0.95$ & 3.42 & 7 & $1.39-1.49$ & 17.32 \\
3 & $0.95-1.08$ & 6.79 & 8 & $1.49-1.60$ & 15.16 \\
4 & $1.08-1.19$ & 10.50 & 1.6 & $1.60-1.74$ & 10.68 \\
5 & $1.19-1.29$ & 13.89 & $1.74-2.14$ & 4.09 \\
\hline
\end{tabular}

\subsection{6 热点分析方法}

生态系统服务热点被定义为具有高服务多样性、高生物物理或货币服务价值或高服务能力的区域 ${ }^{[18]}$ 。 热点区域的识别, 可进一步分析生态系统服务供给能力的强弱。本研究将保护区内各生态系统服务超过各自 平均值的栅格定义为该类服务的热点区域, 将这四类生态系统服务的热点区进行叠加分析, 即可得到卧龙自 然保护区多重生态系统服务热点区的分布状况。在本研究中, 若某桶格单元内 4 种生态系统服务的值均未超 过各自平均值, 则将其定义为非热点区, 若仅有一种生态系统服务的值超过平均值, 则将其定义为 I 类热点 区, 以此类推, 可得到 II 类、III 类、IV类热点区 ${ }^{[18-20]}$ 。

\section{2 结果分析}

2.1 生态系统服务的时空变化

从时间上看,2000-2015 年,NPP、土壤保持、生境质量和水源涵养 4 种服务均呈现增加趋势,该增加趋势 在不同类型生态系统服务的均值、最高值均表现明显,且 4 种服务的增益 (即某生态系统服务 2015 年比 2000 年增加的区域) 面积均显著大于减损 (即某生态系统服务 2015 年比 2000 年减少的区域) 面积 (表 5)。以 NPP 
为例, 其平均值由 2000 年的 $438.95 \mathrm{gC} / \mathrm{m}^{2}$ 增加到 2015 年的 $509.94 \mathrm{gC} / \mathrm{m}^{2}$, 最高值由 2000 年的 $1125.32 \mathrm{gC} / \mathrm{m}^{2}$ 增加到 2015 年的 $1340.69 \mathrm{gC} / \mathrm{m}^{2}$, 增益面积占保护区的 $86.3 \%$ 而减损面积仅占 $13.7 \%$ 。

表 52000 -2015 年卧龙自然保护区生态系统服务变化情况

Table 5 The changes of four ESs in Wolong Nature Reserve from 2000 to 2015

\begin{tabular}{|c|c|c|c|c|c|c|c|c|}
\hline \multirow{2}{*}{$\begin{array}{l}\text { 生态系统服务类型 } \\
\text { Ecosystem services }\end{array}$} & \multicolumn{3}{|c|}{$\begin{array}{c}\text { 平均值 } \\
\text { Mean }\end{array}$} & \multicolumn{3}{|c|}{$\begin{array}{c}\text { 最高值 } \\
\text { Maximum }\end{array}$} & \multicolumn{2}{|c|}{$\begin{array}{c}2000 \text {-2015 年面积变化 } \\
\text { Area change/\% }\end{array}$} \\
\hline & 2000 & 2015 & $\begin{array}{l}\text { 变化率 } \\
\text { Rate/\% }\end{array}$ & 2000 & 2015 & $\begin{array}{l}\text { 变化率 } \\
\text { Rate/\% }\end{array}$ & $\begin{array}{c}\text { 增益面积 } \\
\text { Increased } \\
\text { area }\end{array}$ & $\begin{array}{c}\text { 减损面积 } \\
\text { Decreased } \\
\text { area }\end{array}$ \\
\hline $\mathrm{NPP} /\left(\mathrm{gC} / \mathrm{m}^{2}\right)$ & 438.95 & 509.94 & 16.17 & 1125.32 & 1340.69 & 19.14 & 86.3 & 13.7 \\
\hline $\begin{array}{l}\text { 土壤保持 } /\left(\mathrm{t} \mathrm{hm}^{-2} \mathrm{a}^{-1}\right) \\
\text { Soil Conservation }\end{array}$ & 70.69 & 77.37 & 9.45 & 704.7 & 842.4 & 19.54 & 81.9 & 13.2 \\
\hline 生境质量 Habitat Quality & 0.34 & 0.38 & 11.74 & 1 & 1 & 0 & 11.5 & 2 \\
\hline $\begin{array}{l}\text { 水源涵养/mm } \\
\text { Water Conservation }\end{array}$ & 273.83 & 309.05 & 12.86 & 1140.49 & 1180.44 & 3.50 & 74.5 & 25.2 \\
\hline
\end{tabular}

$\mathrm{NPP}$ : 植被净初级生产力 Net Primary Productivity

从空间上来看,4 种典型生态系统服务从 2000 年到 2015 年均保持了相对稳定的空间格局以及增益面积 超过减损面积的良好趋势,但具体的空间变化区域有所不同(图 2)。NPP 与土壤保持呈现近似的空间分布格 局,即西北一东南方向上由低到高分布,增益面积主要分布在低海拔区,而减损面积主要分布在高海拔区。生 境质量指数呈现东高西低的空间分布特点, 高值区主要位于东部, 北部和西部广大地区以及南部边缘地区生 境质量指数为零, 东南地区增益明显。水源涵养服务的空间分布无明显规律, 其高值零星分布在北部、东部和 南部边缘以及中部部分地区, 低值区不同程度地分布在全域范围内,与生境质量相同的是, 水源涵养的增益区 也在东南区域表现显著。

2.2 不同地形位梯度上生态系统服务的变化

从不同地形位梯度上各生态系统服务均值的分布来看, NPP、土壤保持、生境质量和水源涵养 4 种服务在 2000 年和 2015 年均各自保持相同的趋势, 且 2015 年各服务在不同地形位梯度上的均值均大于 2000 年,但在 具体地形位梯度上的分布有所不同 (图 3)。NPP 和生境质量均呈现随地形位指数增大而递减的趋势,其高值 多分布在较低地形位梯度即海拔较低且坡度较小的地区; 土壤保持随地形位指数增大呈现先增高后降低的趋 势, 其高值主要分布在 5-8 级地形位梯度上; 水源涵养呈现较为起伏波动的趋势, 其高值主要分布在较低地 形位梯度上,最高值分布在 2 级地形位上, 最低值分布在 9 级地形位上。

从不同地形位梯度上生态系统服务变化类型所占的面积来看(图 3),研究区内 NPP、土壤保持和水源涵 养 3 种服务的变化类型均以增益为主,随地形位指数的增大其增益面积比重均呈降低趋势, 减损和不变的面 积比重均呈递增趋势, 其中水源涵养的减损类型面积比增加相对显著, 在 10 级地形位梯度上甚至超过了 $50 \%$ 。生境质量在区域内大部分地区表现为不变,其增益和减损面积比均在低地形位上相对显著,并随地形 位指数增大而逐渐降低, 因海拔高于 $3750 \mathrm{~m}$ 、坡度 $45^{\circ}$ 以上的区域不是大熊猫生境适宜区,所以高地形位梯度 上生境质量没有发生变化。由此来看, 低地形位指数地区是生态系统服务增益优势区,海拔越高、坡度越大的 区域减损面积相对增加。

\section{3 不同土地利用类型上生态系统服务的差异}

不同土地利用类型上生态系统服务供给量存在明显差异 (图 4)。其中林地和草地既是研究区主要的土 地利用类型, 也是生态系统服务供给的主体, 其生态系统服务供给量占保护区总量的 $95 \%$ 以上。从时间来 看, 2000 年不同土地利用类型上 4 种生态系统服务的供给量均表现为: 林地 >草地 > 耕地 $>$ 水域 $>$ 建设用地 $>$ 未 利用地, 其中 NPP、土壤保持、水源涵养 3 种服务在林地上供给量分别为各自总量的 $49.9 \% 、 57.4 \%$ 和 $50.5 \%$, 在草地上的供给量分别为其各自总量的 $48.7 \%$ 、 $41.5 \%$ 和 $48.9 \%$ 。2015 年不同土地利用类型上 4 种生态系统 服务的供给量均表现为: 林地 $>$ 草地 $>$ 水域 $>$ 耕地 $>$ 建设用地 $>$ 未利用地。林地和草地依然是贡献较大的土地利 

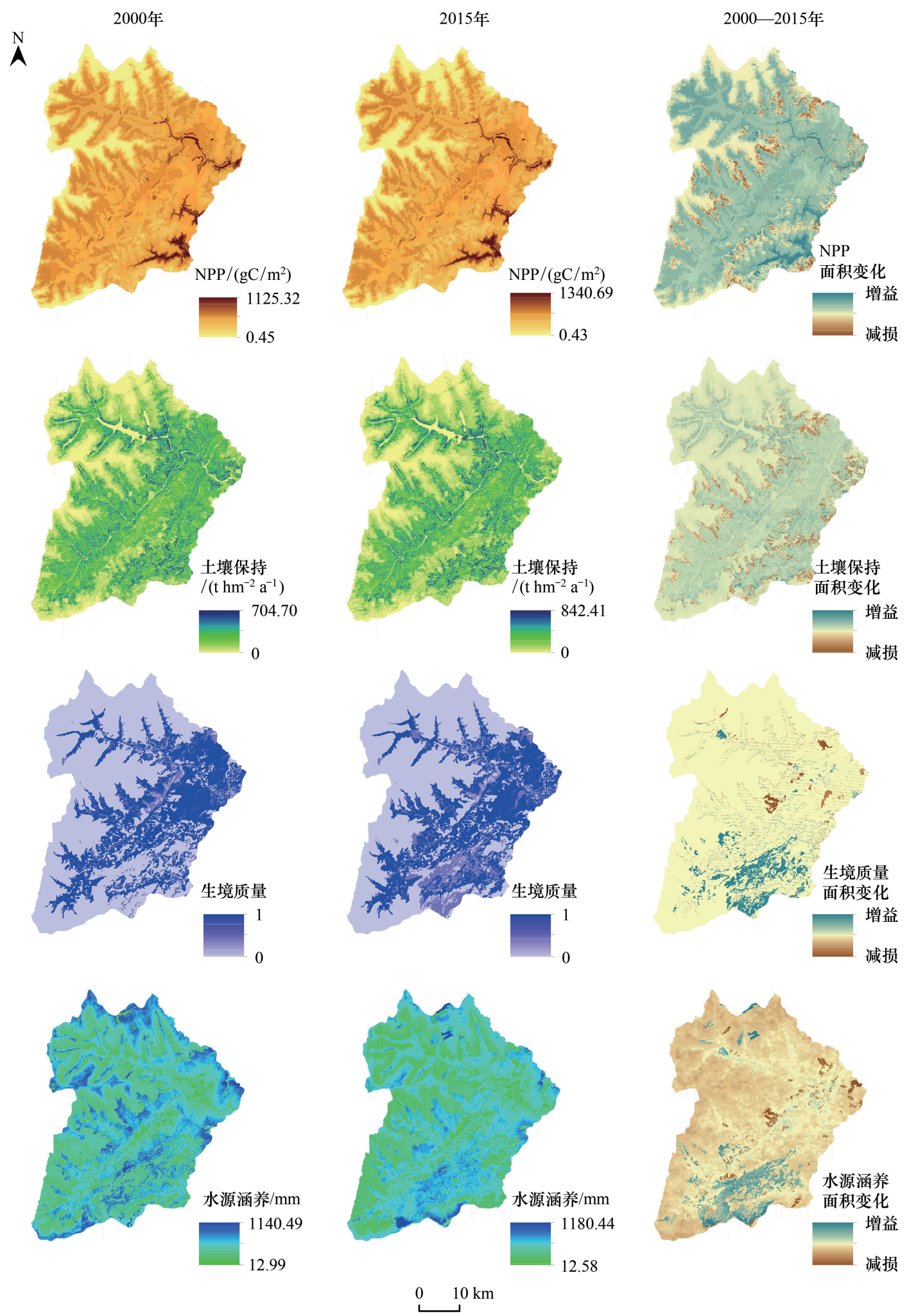

图 2 卧龙自然保护区 2000-2015 年生态系统服务及其变化的空间分布

Fig.2 The spatial distribution of four ESs and their changes in Wolong Nature Reserve from 2000 to 2015 NPP: 植被净初级生产力 Net Primary Productivity;ESs:生态系统服务 Ecosystem Services 

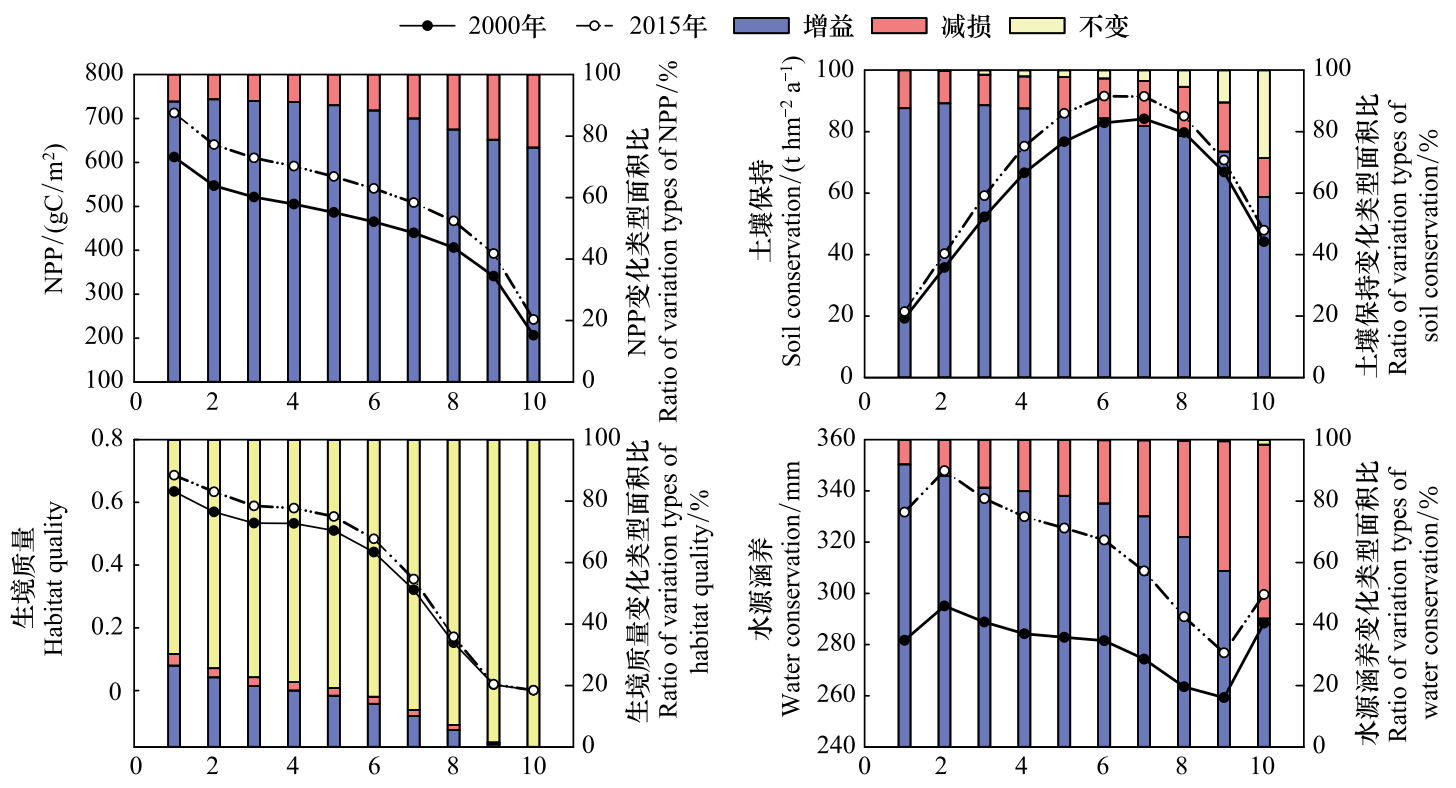

图 3 不同地形位梯度上的生态系统服务均值及其变化类型面积比

Fig.3 The mean value of four ESs and their ratio of variation types at different terrain niche

用类型,但生态系统服务的供给量有所变化,其中林地的生态系统服务供给量有所提升,其提供的 NPP、土壤 保持、水源涵养 3 种服务均达到各自总量的 59\%以上,而草地生态系统服务的供给量有所减少,相应 3 种服务 的供给量均低于各自总量的 40\%,低于 2000 年。此外水域提供的生态系统服务比重超过了耕地。

2000年

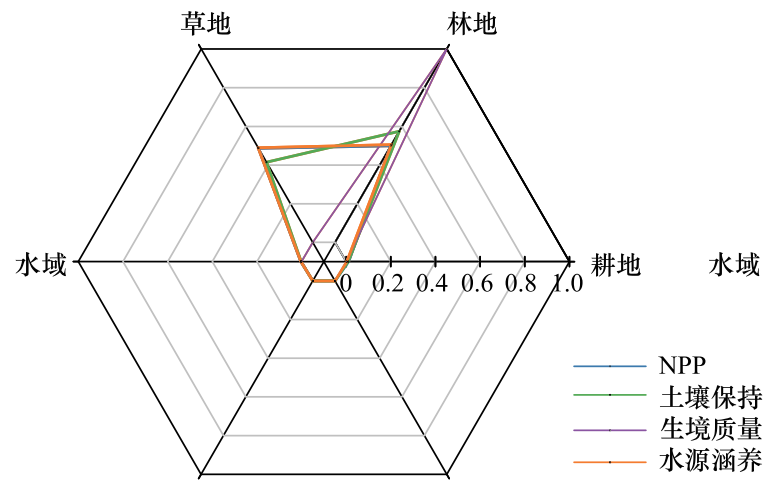

城市建设用地

未利用地
2015年

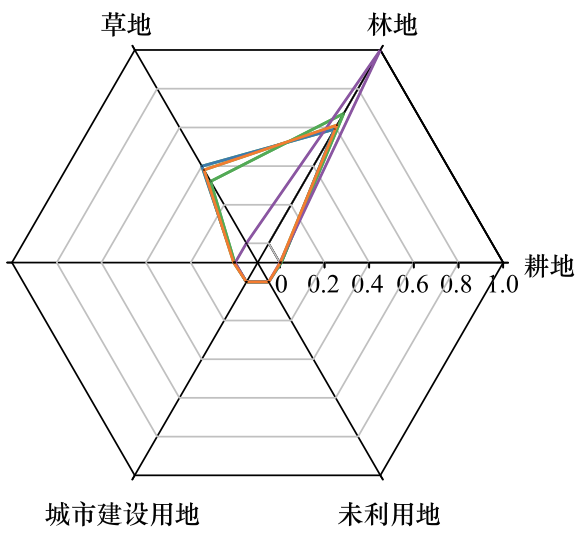

城市建设用地

末利用地

图 42000 年和 2015 年不同土地利用类型上生态系统服务供给量比

Fig.4 The ratio of ecosystem service supply on different land use types in 2000 and 2015

\section{4 热点区分析}

研究区域不同类型热点区的面积变化分析表明 (表 6), 尽管 2000 年和 2015 年四类热点区保持了相同的 数量排序, 即 I 类热点区 $>$ II 类热点区 $>$ III 类热点区 $>I V$ 类热点区, 但是与 2000 年相比, 2015 年IV 类热点区面 积增加显著,增加了 $134.59 \mathrm{~km}^{2}$, 占保护区总面积的 $6.74 \%$ 。非热点区的面积也有所增加, 增加面积为 34.97 $\mathrm{km}^{2}$ 。这两类热点类型增加的面积均来自其相邻类型的热点区, 即 IV 类热点区增加的面积主要来自 III 类热 点区, 而非热点区增加的面积主要来自 I 类热点区 (表 7), II 类热点区则主要转为 III 类热点区 $\left(104.66 \mathrm{~km}^{2}\right)$, 
其次为 I 类热点区 $\left(62.58 \mathrm{~km}^{2}\right)$ 。生态系统服务热点区的变化表明,研究区域整体生态环境改善明显,但是局 部区域生态环境有所退化,且生态环境改善和退化的区域具有渐变特征,因此需要加强 I 类和 III 类热点区的 管理, 预防 I 类热点区的生态环境退化, 同时促进 III 类热点区向 IV 类热点区转化,实现区域生态系统服务供 给的协同和最优化。

从空间分布来看,生态系统服务热点区及其变化具有明显的空间特征(图 5)。研究区域的东部和中部地 区IV 类热点区面积明显高于西部,特别是西北部区域,呈现由东南向西北方向由强变弱的特征。东南部热点 区增加明显, 以 $\mathrm{IV}$ 类热点区最为显著, 此外中部地区, 特别是河流 (皮条河) 两侧 IV 类热点区的增加尤为显著。

表 6 研究区域不同类型热点区面积 $/ \mathbf{k m}^{2}$

Table 6 The area of hotspots in Wolong Nature Reserve

\begin{tabular}{lccc}
\hline 热点区类型 & \multicolumn{2}{c}{} & 面积 Area \\
\cline { 2 - 3 } Types & 2000 & 2015 & $\begin{array}{c}\text { 面积变化 } \\
\text { Area change }\end{array}$ \\
\hline 非热点区 Non-hotspot & $285.65(14.25 \%)$ & $319.62(16.00 \%)$ & $34.97(1.75 \%)$ \\
I 类热点区 Class I hotspot & $584.17(29.25 \%)$ & $491.61(24.61 \%)$ & $-92.56(-4.63 \%)$ \\
II 类热点区 Class II hotspot & $491.36(24.60 \%)$ & $428.49(21.45 \%)$ & $-62.87(-3.15 \%)$ \\
III 类热点区 Class III hotspot & $406.06(20.33 \%)$ & $391.94(19.62 \%)$ & $-14.12(-0.71 \%)$ \\
IV 类热点区 Class IV hotspot & $231.02(11.57 \%)$ & $365.61(18.31 \%)$ & $134.59(6.74 \%)$ \\
总面积 Total & $1997.26(100 \%)$ & $1997.26(100 \%)$ & \\
\hline
\end{tabular}

表 7 研究区域生态系统服务热点区转移矩阵 $/ \mathbf{k m}^{2}$

Table 7 The transfer matrix of hotspots in Wolong Nature Reserve

\begin{tabular}{|c|c|c|c|c|c|c|c|}
\hline \multirow{2}{*}{\multicolumn{2}{|c|}{$\begin{array}{l}\text { 热点区类型 } \\
\text { Types }\end{array}$}} & \multicolumn{5}{|c|}{2015 年 Year 2015} & \multirow{3}{*}{$\begin{array}{l}\text { 转出/\% } \\
\text { Ratio of the area } \\
\text { transferred out } \\
28.33 \%\end{array}$} \\
\hline & & \multirow{2}{*}{$\begin{array}{c}\begin{array}{c}\text { 非热点区 } \\
\text { Non-hotspot }\end{array} \\
204.02\end{array}$} & \multirow{2}{*}{$\begin{array}{c}\text { I 类热点区 } \\
\text { Class I hotspot } \\
43.93\end{array}$} & \multirow{2}{*}{$\begin{array}{c}\begin{array}{c}\text { II 类热点区 } \\
\text { Class II hotspot }\end{array} \\
31.22\end{array}$} & \multirow{2}{*}{$\begin{array}{c}\text { III 类热点区 } \\
\text { Class III hotspot } \\
4.87\end{array}$} & \multirow{2}{*}{$\begin{array}{c}\text { IV类热点区 } \\
\text { Class IV hotspot } \\
0.61\end{array}$} & \\
\hline 2000 年 & 非热点区 & & & & & & \\
\hline & I 类热点区 & 96.75 & 373.26 & 77.70 & 30.80 & 5.65 & $36.10 \%$ \\
\hline & II 类热点区 & 18.04 & 62.58 & 262.14 & 104.66 & 43.93 & $46.65 \%$ \\
\hline & III 类热点区 & 0.75 & 10.08 & 45.56 & 222.70 & 126.98 & $45.16 \%$ \\
\hline & IV类热点区 & 0.06 & 1.76 & 11.87 & 28.91 & 188.44 & $18.43 \%$ \\
\hline \multicolumn{2}{|c|}{$\begin{array}{l}\text { 转人 } / \% \\
\text { Ratio of the area transferred in }\end{array}$} & $36.17 \%$ & $24.07 \%$ & $38.82 \%$ & $43.18 \%$ & $48.46 \%$ & \\
\hline
\end{tabular}

\section{3 讨论}

生态系统服务的时空变化是自然和社会经济因素共同驱动的结果, 总体来看, 2000-2015 年研究区域目 标生态系统服务的供给能力明显加强,生态系统服务之间的协同程度有所提高,一定程度上表明研究区域生 态环境在持续改善和提高,但是部分区域脆弱生态环境依旧存在,空间异质性特征明显。研究区域的东部、东 南和中部地区目标生态系统服务供给量和生态改善特征明显, 而南部边缘、西部和西北部生态脆弱性特征明 显。研究区域目标生态系统服务的空间异质性及其变化与区域地形、土地利用、人类活动以及生态措施等密 切相关。

研究区域目标生态系统服务的分布在不同地形位梯度上分异明显,除土壤保持外,其他生态系统服务的 高值分布区和主要增益区均以低海拔低坡度区域为主, 这可能与两个因素有关:一是研究区域为典型的高山 峡谷区, 气候和植被垂直分异特征明显, 高海拔林线以上发育高山草甸、冰川雪地和裸地 (未利用土地), 而低 海拔和低坡度区域的水热条件更有利于植被的生长和发育; 其次高山峡谷区土地资源紧张, 低海拔低坡度区 域也是人类活动的主要分布区, 居民点和耕地资源集中分布, 但 2000 年前后研究区域大力推进退耕还林, 部 分耕地转化为林地,近十五年的生态恢复效果明显。作为我国生态恢复和建设的重大举措,退耕还林/还草政 

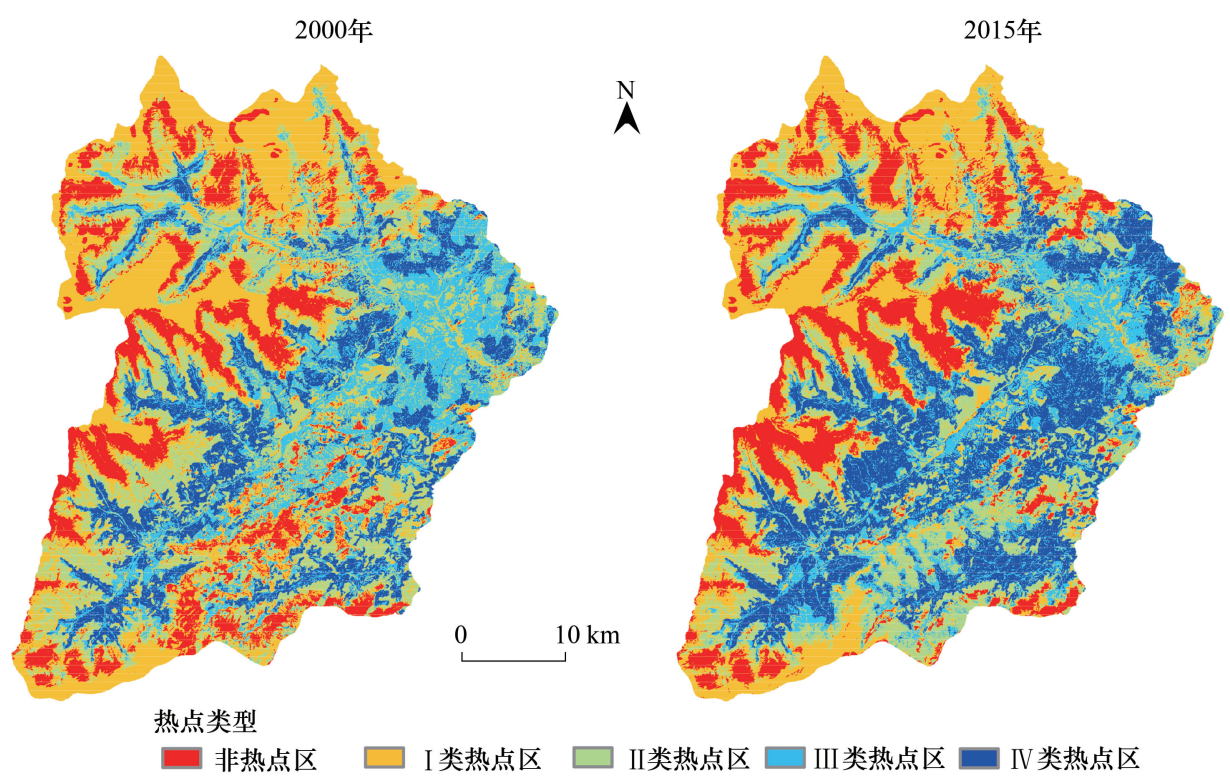

热点类型

非热占区

I类热点区

$\square$ II类热点区 $\square$ III类热点区

IV 类热点区

图 5 卧龙自然保护区 2000 和 2015 年生态系统服务热点区分布

Fig.5 Hotspots of ESs in Wolong Nature Reserve in 2000 and 2015

策的生态效应在各区域正在逐步显现 ${ }^{[21,23]}$, 是近期我国生态改善的主要驱动力之一。

土地利用类型及变化作为影响生态系统服务时空变化的关键因子,通过直接或间接影响生态系统的格局 与过程, 改变生态系统服务的提供能力 ${ }^{[46]}$ 。林地作为生态系统服务的供给量较高的土地利用类型, 是研究区 域目标生态系统服务增加和协同关系提高的主力,也是未来生态改善措施首选的土地利用类型。尽管草地的 生态系统服务贡献较为突出, 但是近年来其供给能力有所下降。研究区域的草地主要为林线以上的高山草 甸, 是在低温大风及瘦薄土壤等生态环境条件下发育的植被类型。草地生态系统服务供给能力下降,可能和 研究区域人类活动有关, 高山草甸是当地牧业 (牦牛等) 和众多中草药资源主要分布场所, 人类利用程度的增 加和干扰增强, 可能是高山草甸生态系统服务供给力降低的主要原因。因此在生态保护和恢复工作中, 除了 目标物种 (大熊猫) 及其生境 (林地) 外, 应该加强草地生态系统的保护和恢复, 避免该脆弱生态系统的退化和 过度利用。

研究区域生态系统的保护和恢复既需要考虑时空异质性, 又要考虑自然和社会经济驱动力。从研究结果 来看,以下三类区域应采取措施,加强保护、恢复或管理:一是以 IV 类热点区为代表的生态保护区,特别是东南 部区域,应该加强生态环境的保护; 其次是以 I 类热点区和 III 类热点区为代表的生态恢复区,预防生态环境 的退化, 促使其向多种生态系统服务协同的方向转化;三是以低海拔低梯度区域和高海拔草地为代表的生态 协调区,人类活动对于该区域生态环境的恢复和退化有决定性作用,建议合理引导或控制人类活动,维护已经 取得的生态恢复成果, 防止脆弱生态系统的进一步退化。

\section{4 结论}

本研究以卧龙自然保护区为例,定量评估了 2000 年和 2015 年碳固定、土壤保持、生境质量和水源涵养 4 种典型生态系统服务的时空分布格局及变化特征,分析了生态系统服务变化的自然和社会经济驱动力, 提出 了分区管理的建议,对保护区的生态保护、恢复和管理有一定的借鉴作用。研究结果揭示了生态系统服务变 化的时空异质性,表明在一定的区域内生态环境改善和退化可能并存,生态保护和恢复须因地制宜, 甄别关键 区域,制定针对性的政策。其次生态系统服务的变化既受自然因素的控制, 又受人为因素的影响,生态恢复/ 建设工程不仅要关注生态系统服务供给能力较高的生态系统类型 (如林地), 也要关注人类活动干扰较大的 
相对脆弱的生态系统类型(如研究区域的草地),保护区域生态系统的多样性。

本文也存在如下不足:一是由于数据获取困难,本研究仅选取了 4 种典型生态系统服务,未来需增加生态 系统服务类型, 特别是与保护区生态保护和人类活动相关的生态系统服务类型;二是需要延长研究年份, 将生 态系统服务的连续变化与土地利用类型的连续变化相联系,定量评估生态建设工程对于生态系统服务变化的 贡献; 三是由于篇幅所限,仅考虑了 4 种典型生态系统服务的时空变化, 没有考虑生态系统服务之间的权衡/ 协同关系,特别是生境质量与其他类型生态系统服务的权衡/协同关系。在以后工作中,须逐步增加数据的获 取分析,拓展并深化研究主题, 为提升生态系统服务供给水平,促进生态保护和恢复提供借鉴。

\section{参考文献 (References) :}

[ 1 ] Millennium Ecosystem Assessment. Ecosystem and Human Well-Being: A Framework for Assessment. Washington, DC: Island Press, 2003.

[ 2 ] 刘绿怡, 刘慧敏, 任嘉衍, 市子元, 丁圣彦. 生态系统服务形成机制研究进展. 应用生态学报, 2017, 28(8): 2731-2738.

[ 3 ] 白永飞, 黄建辉, 郑淑霞, 潘庆民, 张丽霞, 周华坤, 徐海量, 李玉霖, 马健. 草地和荒漠生态系统服务功能的形成与调控机制. 植物生 态学报, 2014, 38(2) : 93-102.

[ 4 ] Ma S, Qiao Y P, Wang L J, Zhang J C. Terrain gradient variations in ecosystem services of different vegetation types in mountainous regions: Vegetation resource conservation and sustainable development. Forest Ecology and Management, 2021, 482: 118856.

[ 5 ] Sun X Y, Shan R F, Liu F. Spatio-temporal quantification of patterns, trade-offs and synergies among multiple hydrological ecosystem services in different topographic basins. Journal of Cleaner Production, 2020, 268: 122338.

[ 6 ] Hao R F, Yu D Y, Liu Y P, Liu Y, Qiao J M, Wang X, Du J S. Impacts of changes in climate and landscape pattern on ecosystem services. Science of the Total Environment, 2017, 579: 718-728.

[ 7 ] Zhong L N, Wang J, Zhang X, Ying L X. Effects of agricultural land consolidation on ecosystem services: Trade-offs and synergies. Journal of Cleaner Production, 2020, 264: 121412.

[ 8 ] Quintas-Soriano C, Castro A J, Castro H, García-Llorente M. Impacts of land use change on ecosystem services and implications for human wellbeing in Spanish drylands. Land Use Policy, 2016, 54: 534-548.

[ 9 ] Han R, Feng C C, Xu N Y, Guo L. Spatial heterogeneous relationship between ecosystem services and human disturbances: A case study in Chuandong, China. Science of the Total Environment, 2020, 721: 137818.

[10] Raudsepp-Hearne C, Peterson G D, Bennett E M. Ecosystem service bundles for analyzing tradeoffs in diverse landscapes. Proceedings of the National Academy of Sciences of the United States of America, 2010, 107(11) : 5242-5247.

[11] Schröter M, Remme R P. Spatial prioritisation for conserving ecosystem services: comparing hotspots with heuristic optimisation. Landscape Ecology, 2016, 31(2): 431-450.

[12] Dubois L, Mathieu J, Loeuille N. The manager dilemma: Optimal management of an ecosystem service in heterogeneous exploited landscapes. Ecological Modelling, 2015, 301: 78-89.

[13] Nahuelhual L, Benra F, Laterra P, Marin S, Arriagada R, Jullian C. Patterns of ecosystem services supply across farm properties: Implications for ecosystem services-based policy incentives. Science of the Total Environment, 2018, 634: 941-950.

[14] Birch J C, Newton A C, Aquino C A, Cantarello E, Echeverria C, Kitzberger T, Schiappacasse I, Garavito N T. Cost-effectiveness of dryland forest restoration evaluated by spatial analysis of ecosystem services. Proceedings of the National Academy of Sciences, 2010,107 ( 50) : 21925- 21930.

[15] Hou Y, Lü Y H, Chen W P, Fu B J. Temporal variation and spatial scale dependency of ecosystem service interactions: a case study on the central Loess Plateau of China. Landscape Ecology, 2017, 32(6) : 1201-1217.

[16] Sun X, Lu Z M, Li F, Crittenden J C. Analyzing spatio-temporal changes and trade-offs to support the supply of multiple ecosystem services in Beijing, China. Ecological Indicators, 2018, 94 : 117-129.

[17] Braun D, Damm A, Hein L, Petchey O L, Schaepman M E. Spatio-temporal trends and trade-offs in ecosystem services: An Earth observation based assessment for Switzerland between 2004 and 2014. Ecological Indicators, 2018, 89: 828-839.

[18］王晓峰, 薛亚永, 张园. 基于地形梯度的陕西省生态系统服务价值评估. 冰川冻土, 2016, 38(5)：1432-1439.

[19］潘竟虎, 李真. 干旱内陆河流域生态系统服务空间权衡与协同作用分析. 农业工程学报, 2017, 33(17) : 280-289.

[20] 再风维, 罗志军, 吴佳平, 齐松, 曹丽萍, 蔡正妹, 陈瑶瑶. 鄱阳湖地区生态系统服务权衡与协同关系的时空格局. 应用生态学报, 2019, 30(3) : 995-1004.

[21] 许丁雪, 吴芳, 何立环, 刘海江, 江源. 土地利用变化对生态系统服务的影响——张家口-承德地区为例. 生态学报, 2019, 39(20): 
7493-7501

[22] Anaya-Romero M, Muñoz-Rojas M, Ibáñez B, Marañón T. Evaluation of forest ecosystem services in Mediterranean areas. A regional case study in South Spain. Ecosystem Services, 2016, 20: 82-90.

[23］苏常红, 王亚璐. 汾河上游流域生态系统服务变化及驱动因素. 生态学报, 2018, 38(22)：7886-7898.

[24］潘梅, 陈天伟, 黄麟, 曹巍. 京津冀地区生态系统服务时空变化及驱动因素. 生态学报, 2020, 40(15) : 5151-5167.

[25] 郡全琴, 刘纪远, 黄麟, 焚江文, 徐新良, 王军邦. 2005-2009 年三江源自然保护区生态保护和建设工程生态成效综合评估. 地理研究, 2013, 32(9): 1645-1656.

[26] Wang J T, Peng J, Zhao M Y, Liu Y X, Chen Y Q. Significant trade-off for the impact of Grain-for-Green Programme on ecosystem services in North-western Yunnan, China. Science of the Total Environment, 2017, 574: 57-64.

[27] Xu W H, Xiao Y, Zhang J J, Yang W, Zhang L, Hull V, Wang Z, Zheng H, Liu J G, Polasky S, Jiang L, Xiao Y, Shi X W, Rao E M, Lu F, Wang X K, Daily G C, Ouyang Z Y. Strengthening protected areas for biodiversity and ecosystem services in China. Proceedings of the National Academy of Sciences, 2017, 114(7): 1601-1606.

[28］宗雪. 森林类型自然保护区生态系统服务价值评估一一卧龙自然保护区为例 [D ]. 北京: 北京林业大学, 2008.

[29] Wang J, Feng L, Palmer P I, Liu Y, Fang S X, Bösch H, O'Dell C W, Tang X P, Yang D X, Liu L X, Xia C Z. Large Chinese land carbon sink estimated from atmospheric carbon dioxide data. Nature, 2020, 586(7831) : 720-723.

[30］朱文泉, 潘耀忠, 张锦水. 中国陆地植被净初级生产力遥感估算. 植物生态学报, 2007, 31 (3): 413-424.

[31］陆传豪，代富强，刘刚才. 基于 GIS 和 RUSLE 模型的万州区土壤保持服务功能空间分布特征. 长江流域资源与环境，2017，26(8)： 1228-1236.

[32］薛亚永，王晓峰. 黄土高原森林草原区退耕还林还草土壤保持效应评估. 干旱地区农业研究，2017，35(5)：122-128.

[33] 任志远, 刘炎序. 西北地区植被保持土壤效应评估. 资源科学, 2013, 35(3) : 610-617.

[34] Wischmeier W H, Johnson C B, Cross B V. A soil erodibility nomograph for farmland and construction sites. Journal of Soil and Water Conservation, 1971, 26: 189-193.

[35] Belasri A, Lakhouili A. Estimation of soil erosion risk using the universal soil loss equation (USLE) and geo-information technology in Oued El Makhazine watershed, morocco. Journal of Geographic Information System, 2016, 8(1) : 98-107.

[36］肖洋,欧阳志云, 徐卫华, 肖淡, 肖强. 基于 GIS 重庆土壤侵蚀及土壤保持分析. 生态学报, 2015，35(21)：7130-7138.

[37] 蔡崇法, 丁树文, 史志华, 黄丽, 张光远. 应用 USLE 模型与地理信息系统 IDRISI 预测小流域土壤侵蚀量的研究. 水土保持学报, 2000, $14(2): 19-24$.

[38] 包玉斌, 刘康, 李婷, 胡胜. 基于 InVEST 模型的土地利用变化对生境的影响一一陕西省黄河湿地自然保护区为例. 干旱区研究, $2015,32(3): 622-629$.

[39］欧阳志云, 刘建国, 肖寒, 谭迎春, 张和民. 卧龙自然保护区大熊猫生境评价. 生态学报, 2001, 21(11) : 1869-1874.

[40］杨渺，欧阳志云，徐卫华，龙泉，谢强. 卧龙大熊猫潜在适宜生境及实际利用生境评价. 四川农业大学学报，2017，35(1)：116-123.

[41] 白文科, 张晋东, 杨霞, 迟文峰, 董金金, 李程, 古晓东, 周材权. 基于 GIS 的卧龙自然保护区大熊猫生境选择与利用. 生态环境学报, 2017, 26(1): 73-80.

[42］张宏锋，袁素芬. 东江流域森林水源涵养功能空间格局评价. 生态学报, 2016, 36(24)：8120-8127.

[43] 包玉斌, 李婷, 柳辉, 马涛, 王怀香, 刘康, 沈茜, 刘心浩. 基于 InVEST 模型的陕北黄土高原水源涵养功能时空变化. 地理研究, 2016, 35(4): 664-676.

[44] 顾铮鸣, 金晓斌, 沈春竹, 金志丰, 周寅康. 近 15a 江苏省水源涵养功能时空变化与影响因素探析. 长江流域资源与环境, 2018, 27 (11) : 2453-2462.

[45] 徐彩仙, 巩杰, 李炎, 燕玲玲, 高秉丽. 基于地形梯度的甘肃白龙江流域典型生态系统服务分布特征. 生态学报, 2020, 40(13)： 4291-4301.

[46] 傅伯杰, 张立伟. 土地利用变化与生态系统服务: 概念、方法与进展. 地理科学进展, 2014, 33(4) : 441-446. 